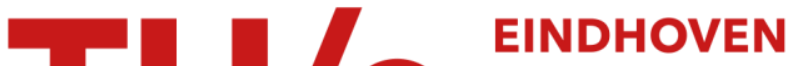 UNIVERSITY OF TECHNOLOGY
}

\section{Feasibility and performance assessment of commercial PV inverters operating with droop control for providing voltage supports services}

\author{
Citation for published version (APA): \\ Vergara, P. P., Mai, T. T., Burstein, A., \& Nguyen, P. H. (2019). Feasibility and performance assessment of \\ commercial $\mathrm{PV}$ inverters operating with droop control for providing voltage supports services. In Proceedings of \\ 2019 IEEE PES Innovative Smart Grid Technologies Europe, ISGT-Europe 2019 [8905499] Institute of Electrical \\ and Electronics Engineers. https://doi.org/10.1109/ISGTEurope.2019.8905499
}

DOI:

10.1109/ISGTEurope.2019.8905499

Document status and date:

Published: 01/09/2019

\section{Document Version:}

Accepted manuscript including changes made at the peer-review stage

\section{Please check the document version of this publication:}

- A submitted manuscript is the version of the article upon submission and before peer-review. There can be important differences between the submitted version and the official published version of record. People interested in the research are advised to contact the author for the final version of the publication, or visit the DOI to the publisher's website.

- The final author version and the galley proof are versions of the publication after peer review.

- The final published version features the final layout of the paper including the volume, issue and page numbers.

Link to publication

\footnotetext{
General rights

- You may freely distribute the URL identifying the publication in the public portal. follow below link for the End User Agreement:

www.tue.nl/taverne

\section{Take down policy}

If you believe that this document breaches copyright please contact us at:

openaccess@tue.nl

providing details and we will investigate your claim.
}

Copyright and moral rights for the publications made accessible in the public portal are retained by the authors and/or other copyright owners and it is a condition of accessing publications that users recognise and abide by the legal requirements associated with these rights.

- Users may download and print one copy of any publication from the public portal for the purpose of private study or research.

- You may not further distribute the material or use it for any profit-making activity or commercial gain

If the publication is distributed under the terms of Article $25 \mathrm{fa}$ of the Dutch Copyright Act, indicated by the "Taverne" license above, please 


\title{
Feasibility and Performance Assessment of Commercial PV Inverters Operating with Droop Control for Providing Voltage Support Services
}

\author{
Pedro P. Vergara ${ }^{1}$, Tam T. Mai ${ }^{1}$, Andrew Burstein ${ }^{2}$, and Phuong H. Nguyen ${ }^{1}$ \\ ${ }^{1}$ Dep. of Electrical Engineering, Eindhoven University of Technology, Eindhoven, The Netherlands \\ Emails: \{p.p.vergara.barrios, t.t.mai, p.nguyen.hong\} @ tue.nl \\ ${ }^{2}$ Flex Power Grid Laboratory, DNV GL, Arnhem, The Netherlands \\ Email: andrew.burstein@dnvgl.com
}

\begin{abstract}
The proliferation of PV generation systems connected to electrical distribution systems (EDSs) brings many operational challenges, and within them, over-voltage issues are regarded as the most critical. Among all the strategies available to handle these over-voltage issues, those implemented locally at the PV inverters seem to be the more promising, considering their distributed and easy-to-implement features. In this paper, the feasibility and performance assessment of a commercial PV inverter for mitigating over-voltage events in an EDS is presented. To do this, an active and reactive droop-based voltage control strategy is implemented in a commercial inverter. Realtime power hardware-in-the-loop (PHIL) laboratory tests were performed to assess the PV inverter's efficiency when absorbing reactive power, as well as its interaction with the distribution grid. According to the obtained results, the PV inverter's efficiency was not noticeably affected by the changes in reactive power. Additionally, the PV inverter responded accordingly, following the voltage control strategy implemented, providing successfully the expected voltage support services.
\end{abstract}

Index Terms-PV inverters, droop control, real-time simulations, over-voltage events.

\section{INTRODUCTION}

The proliferation of PV generation systems connected to electrical distribution systems (EDSs) brings many operational challenges that the distribution network operators have to face. These challenges are mainly associated with over-voltage issues, especially during times with high PV generation and low consumption; and fast transients due to natural cloud movements [1]. These technical issues have important consequences in the operation of the EDSs, as they might increase the frequency of tap changes in on-load tap changing distribution transformers (reducing their life-time spans), as well as limiting the integration of new PV installations [2], [3].

Considering this, all the stakeholders involved are putting in a significant effort to ensure a reliable and secure operation of EDSs with high PV penetration [4]. Among the strategies developed to mitigate over-voltage issues in PV-rich EDSs, it is possible to find [5]: infrastructure (network) reinforcement, active voltage regulators, such as SVCs and STATCOMs; and advance PV inverter control strategies. Regarding the PV inverter control strategies, multiple approaches can be found in the literature, including: reactive power control (RPC) [6],
[7], power factor control (PFC), and active power control (APC) [8]. All these strategies are generally based on simple control rules using electrical quantities such as voltage magnitude or power quality indexes [9], [10]. Usually, when RPC control is implemented, if the voltage magnitude at the point of connection (POC) of the inverter surpasses a voltage threshold, the inverter starts absorbing a certain amount of reactive power, and as a consequence, the voltage at the POC is reduced. In case of an under-voltage, the PV inverter start injecting reactive power, increasing the voltage magnitude at the POC. In APC, when the voltage magnitude at the POC surpasses a certain voltage threshold, the active power injected by the PV inverter is reduced (curtailed) [11]. In general, APC is more effective than RPC given the highly resistive line characteristics of low voltage EDSs [8]. Nevertheless, a coordinated approach that merge both controls (APC and RPC) has shown to be the most promising technical approach, as demonstrated by [12]-[14], reducing simultaneously the overload of the distribution transformers due to the absorption of reactive power by the $\mathrm{PV}$ inverters and the amount of active power curtailed.

Although effective, strategies such as the ones presented in [12]-[14] require the deployment of a large (and complex) communication infrastructure, enabling all the PV inverters (and other equipment) connected in the EDS to exchange information. This feature limits the large-scale implementation of such strategies. To overcome this, works such as [15][18], has proposed locally implemented strategies at the PV inverter and based on the well-known droop control. The main advantages of these droop-based APC and RPC strategies is their distributed and easy-to-implement features [15]. Nevertheless, the interaction of such droop-based control strategies (implemented in a commercial PV inverter) and the distribution network has not been tested at laboratory level yet.

Considering this, the main contribution of this paper is related to the feasibility and performance assessment of a commercial PV inverter and its capability to mitigate overvoltage events in an EDS. To do this, firstly, isolated tests were performed in order to assess the PV inverters: (i) efficiency, due to the operation of RPC strategy and; (ii) response time, 


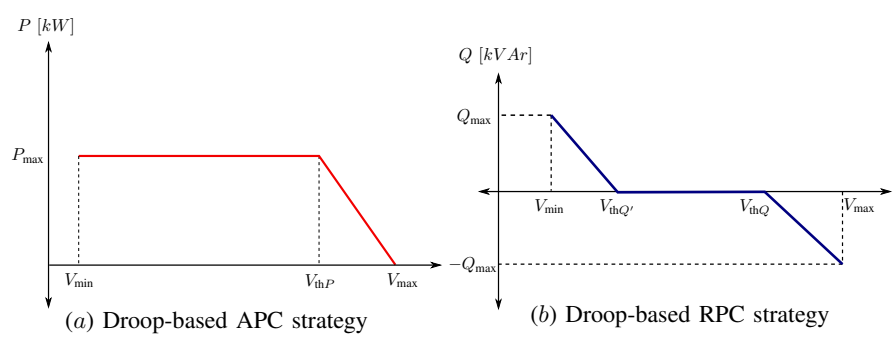

Figure 1. Droop-based APC and RPC. In the case of coordinated APC-RPC $V_{\text {th } Q}$ is set equal to $V_{\mathrm{th} P}$. For under-voltage, a voltage magnitude threshold is also defined, $V_{\text {th } Q^{\prime}}$.

under a sudden increase/decrease in the voltage at the POC. Secondly, real-time (RT) power hardware-in-the-loop (PHIL) simulations were performed in order to test the PV inverter interaction with a distribution network.

This paper is structure as follows: Sec. II introduce the main features of droop-based APC and RPC strategies. Then, Sec. III presents the experimental setup used and the results obtained based on the laboratory measurements performed. Finally, conclusions are drawn in Sec. IV.

\section{DROOP-BASEd APC AND RPC STRATEGIES}

Droop control is a well-known approach used for power sharing among multiple distributed generation units running in parallel [19]. In general, the standard droop control strategy runs continuously with only local measurements. Thus, droopbased APC and RPC can be implemented in the inverter's control system, following the strategy defined in Fig. 1, where $P_{\max }$ and $Q_{\max }$ represents the maximum active and reactive power output set by the control, respectively; and $V_{\mathrm{th} P}$ and $V_{\mathrm{th} Q}$ represent the voltage thresholds after which APC and RPC are activated. In the case of coordinated APC-RPC, $V_{\mathrm{th} Q}$ is set equal to $V_{\mathrm{th} P}$ [18]. The definition of these parameters, including the maximum and minimum voltage magnitude limits, must take into account the European Standard EN 50160. Notice that as droop-based APC and RPC runs continuously, the inverters control must be able to follow the voltage at the POC and simultaneously update the maximum power point (MPP) generation. These features are usually available in the last generation of commercial inverters.

\section{EXPERIMENTAL RESULTS}

In this section, first, the experimental setup used is described. Then, experimental results are presented and analyzed.

\section{A. Experimental Setup}

In the test, both the AC distribution network and the PV array (DC input) are emulated using realistic, full-scale power emulators. This allows the full operating range of the commercial PV inverter, both for AC and DC sides. The AC distribution network and the PV emulators consists of high-bandwidth power amplifiers driven by a real-time simulator models of the grid and PV arrays. The features of the commercial PV inverter under test are presented in Table I. The schematic representation of the real-time PHIL setup is
Table I

INVERTER'S TECHNICAL SPECIFICATION

\begin{tabular}{cc}
\hline DC Max. Input Voltage & $1100\left[V_{\mathrm{dc}}\right]$ \\
\hline Num. MPPTs & 4 \\
\hline DC Max. Input Current (per MPPT) & $28.5[A]$ \\
\hline$I_{\mathrm{sc}}$ (per MPPT) & $44.5[A]$ \\
\hline DC MPP Range & $200-1000\left[V_{\mathrm{dc}}\right]$ \\
\hline AC Nominal Output Voltage & $400\left[\mathrm{~V}_{\mathrm{ac}}\right]$ \\
\hline AC Nominal Output Frequency & $50[\mathrm{~Hz}]$ \\
\hline Rated Active Output Power & $50[\mathrm{~kW}]$ \\
\hline AC Max. Output Power $\left(S_{0}\right)$ & $55[\mathrm{kV}]$ \\
\hline AC Max. Output Current & $83.3[\mathrm{~A}]$ \\
\hline
\end{tabular}

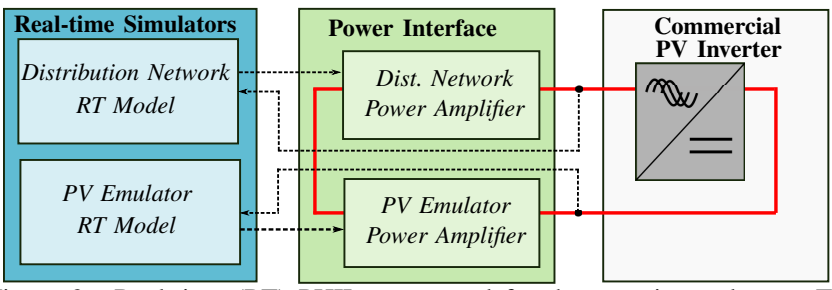

Figure 2. Real-time (RT) PHIL setup used for the experimental tests. The red lines represent flow of active and reactive power. The dashed black lines represent data/measurement flow.

shown in Fig. 2, displaying the interface and connections between the real-time simulators, the power amplifiers and the commercial PV inverter. As can be seen in Fig. 2, the physical measurements are taken from the output of the power amplifiers, then, fed back into the real-time simulator, which recalculate their outputs. In this way, the model is able to represent and respond to the dynamic operation of the PV inverter within the simulated distribution network.

\section{B. Inverter's Efficiency and Droop Control Performance}

This first test was built with the aim of measuring any decrease in the inverter's efficiency (i.e., measuring any extra losses) due to controlling its reactive power output, when compared with the case $\cos \phi=1$. Thus, efficiency is calculated as,

$$
\eta_{\mathrm{inv}}=\frac{P_{\mathrm{ac}}}{P_{\mathrm{dc}}}[\%]
$$

For this test, the inverter was operated at nominal output power. The PV emulator was set with the information shown in Table II, with irradiance of $1000 \mathrm{~W} / \mathrm{m}^{2}$. The droop control settings to implement APC and RPC are presented in Table III and Table IV, respectively; and plotted as continuous lines also in Fig. 3. The results from this test are displayed in Fig. 3. To obtain this, the AC voltage is stepped up and down in steps of 0.01 p.u. from 1.0 p.u. to 1.1 p.u., and from 1.0 p.u. to 0.9 p.u.. Each step is measured for 2 minutes in steady-state operation, and the efficiency is calculated using the average of the measurements.

As can be seen Fig. 3, the inverter's efficiency is mostly affected by the active power output, decreasing sharply when the active power is reduced to less than 24\%. Thus, it is expected that if APC is implemented, and the voltage of the POC is close to the maximum limit, the inverter will operate with an efficiency near to $90 \%$. Similarly, when the voltage 


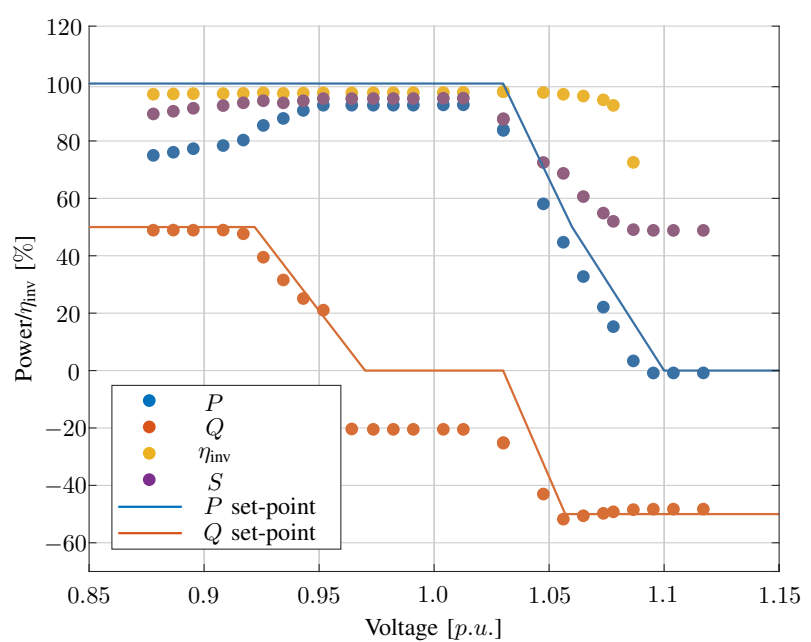

Figure 3. Measured active and reactive power (as a percentage of the inverter's nominal output power, $S_{0}=55 \mathrm{kVA}$ ) vs. voltage. Inverter's efficiency vs. voltage.

Table II

PV SETTINGS FOR NOMINAL OPERATION

\begin{tabular}{cccccc}
\hline \hline$V_{\mathrm{oc}}$ & $I_{\mathrm{sc}}$ & $I r r$ & $V_{\mathrm{mp}}$ & $I_{\mathrm{mp}}$ & $P_{\mathrm{mp}}$ \\
\hline$[V]$ & {$[A]$} & {$\left[W / m^{2}\right]$} & {$[V]$} & {$[A]$} & {$[\mathrm{kW}]$} \\
\hline 730 & 100 & 1000 & 584.1 & 90.4 & 52.8 \\
\hline \hline
\end{tabular}

decreases, the efficiency also decreases up to $96 \%$ from the maximum measured efficiency of $96.6 \%$. It is important to highlight that when the voltage decreases at the POC, and the RPC strategy is implemented following the defined droop settings, the active power also decreases, in this case reaching a value near to $80 \%$ at the lowest applied voltage. This decrease in the active power is due to the inverter's internal protections, activated due to the overcurrent caused by the low AC-side voltage.

Finally, noticed in Fig. 3 that in nominal operation, the reactive power consumption of the device was measure to be $20 \%$ of the nominal output power $\left(S_{0}\right)$. It was not possible to explain this behaviour, and according to the manufacturer, it can be due to an error in the control upgrade done in order to implement the droop control settings. This is currently under investigation by the inverter's manufacturer.

\section{Inverter's Response Time}

This test was performed in order to understand how fast the inverter's voltage regulation control will respond to a change in voltage at the POC. In this test, the AC voltage is stepped up from 1.0 p.u. to 1.1 p.u., then down to 0.9 p.u., and then back to 1.0 p.u.. Each step is made after the PV inverter has reached a new steady state of operation. Results are displayed in Fig. 4, and the measured response times in Table V. Rise and falls times were measured from the previous steady-state voltage magnitude to the point of $90 \%$ of the new steadystate value. As expected, the inverter's response time it is within the operational time of power electronics i.e., below $600 \mathrm{~ms}$. Thus, it is possible to conclude that APC and RPC implemented through the PV inverters control algorithms are sufficiently fast to be used as a tool for performing voltage regulation.
Table III

$P-V$ DROOP TO IMPLEMENT APC

\begin{tabular}{cc}
\hline \hline$V[p . u]$. & $P\left[\% S_{0}\right]$ \\
\hline 1.03 & 100 \\
\hline 1.06 & 50 \\
\hline 1.10 & 0 \\
\hline \hline
\end{tabular}

Table IV

$Q-V$ DROOP TO IMPLEMENT RPC

\begin{tabular}{cc}
\hline \hline$V[p . u]$. & $Q\left[\% S_{0}\right]$ \\
\hline 0.92 & 50 Leading \\
\hline 0.97 & 0 \\
\hline 1.03 & 0 \\
\hline 1.06 & 50 Lagging \\
\hline \hline
\end{tabular}

\section{Real-Time PHIL Operation}

In this final test, the inverter's performance is tested using the full real-time PHIL set up. In this test, the current at the POC is measured back into the distribution network model and the model and physical output voltage responds accordingly. The model used corresponds to the one presented in Fig. 2. Results are displayed in Fig. 5, while Fig. 6 and Fig. 7 display a zoom view for some specific time periods of the real-time simulations. All the measurements were taken from the ACside of the inverter.

From time $50 \mathrm{~s}$ to $186 \mathrm{~s}$, the inverter is initialized, but its output current is not fed back into the PHIL model. The irradiance was set initially to $200 \mathrm{~W} / \mathrm{m}^{2}$ and then adjusted. Fig. 6 displays the output power changing in steps, each of these steps corresponds to a change in the set irradiance value in the PV emulator.

At time $186 s$, the inverter is connected and the PHIL model is thus in full operation. Notice in Fig. 6 that as the irradiance of the PV emulator is changed, the voltage of the PV inverters at the POC also changes, and as as consequence, the PV inverter starts consuming reactive power (RPC strategy), while the active power is also reduced (APC strategy). Based on this, it is possible to conclude that droop control operates as expected.

At time $290 \mathrm{~s}$, the irradiance is suddenly reduced to $0 \mathrm{~W} / \mathrm{m}^{2}$, which causes the inverter to disconnect its output. Then, the irradiance is stepped up to $1000 \mathrm{~W} / \mathrm{m}^{2}$. The slow rise in the output power that can be seen in Fig. 5 from $310 \mathrm{~s}$ to $500 \mathrm{~s}$ corresponds to the inverters internal controls which restricts the ramp rate of output power when reconnecting after a disconnection.

At time $650 \mathrm{~s}$, the grid voltage is decreased. This action also reduces the voltage at the POC of the PV inverter. Notice in Fig. 5 that once the PV inverter perceived the change in the POC voltage, it begins to operate at nominal power (recalling that in nominal operation a reactive power of $20 \% S_{0}$ was measured). After time $650 \mathrm{~s}$, several changes in the irradiance and grid voltage were performed, as shown in Fig. 7, in order to test in real-time the interaction between the distribution network and the PV inverter operating with the droop-based APC-RPC strategy. The interactions were 


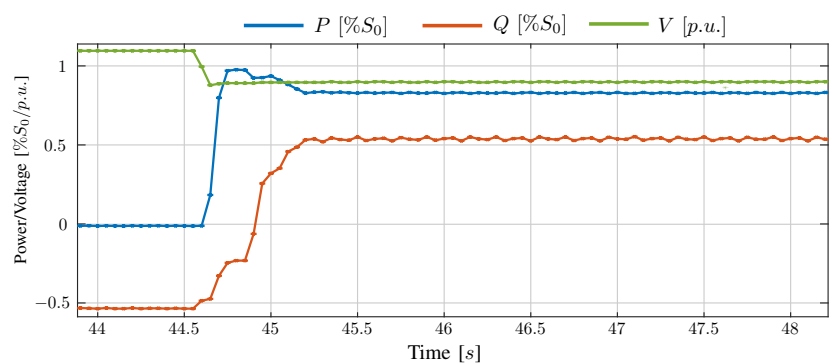

(a) Measurement of $P$ and $Q$ when $V$ goes from 1.1 p.u. to 0.9 p.u..

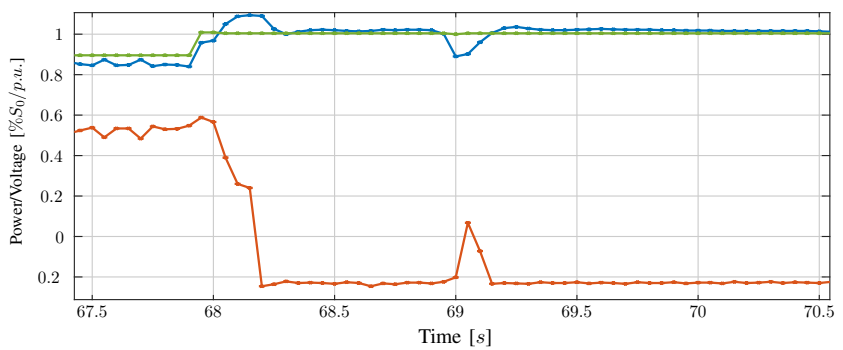

(b) Measurement of $P$ and $Q$ when $V$ goes from 0.9 p.u. to 1.0 p.u.

Figure 4. Response time of the commercial PV inverter after a change in the voltage at the POC.

Table V

INVERTER'S RESPONSE TIME

\begin{tabular}{ccc}
\hline \hline$U_{\text {set }}[p . u]$. & $P[m s]$ & $Q[m s]$ \\
\hline $1.0-1.1$ & 400 & 100 \\
\hline $1.1-0.9$ & 150 & 600 \\
\hline $0.9-1.0$ & 150 & 250 \\
\hline \hline
\end{tabular}

performed sequentially as described next:

- When the irradiance decreased from $1000 \mathrm{~W} / \mathrm{m}^{2}$ to $400 \mathrm{~W} / \mathrm{m}^{2}$, the output active power also decreased. As a under-voltage was perceived, the PV inverter start injecting reactive power.

- When the irradiance increased from $400 \mathrm{~W} / \mathrm{m}^{2}$ to $800 \mathrm{~W} / \mathrm{m}^{2}$, the output active power increased. An acceptable voltage appeared at the POC. Thus, the reactive power drops to its nominal operation output.

- When the grid voltage was increased from 0.9 p.u. to 1.0 p.u., an over-voltage appeared at the POC. Thus, reactive power absorption is increased at its maximum (RPC strategy), while the active power is reduced (APC strategy).

- When the irradiance increased from $800 \mathrm{~W} / \mathrm{m}^{2}$ to $1000 \mathrm{~W} / \mathrm{m}^{2}$, no noticeable change was observed, as the PV inverter was already operating at its maximum capacity.

- When the grid voltage was decreased from 1.0 p.u. to 0.9 p.u., the voltage at the POC drops to an acceptable value, and the inverter started operating once again in nominal operation.

- When the irradiance decreased to $0 \mathrm{~W} / \mathrm{m}^{2}$, the output active power droped to $0 \mathrm{~kW}$. An under-voltage appeared at the POC and the PV inverter started increasing its reactive power output.

- After a short period of time, the PV inverter sensed no irradiance, and thus, disconnected its $\mathrm{AC}$-side.

\section{E. Reflections on Technical Issues}

Some technical issues were found during development and running of the tests: a non-expected reactive power consumption from the PV inverters at nominal operation (close to $20 \%$ ), which is currently under investigation by the inverter's manufacturer. Additionally, although different inverters (from different manufacturers) were available for testing (within this research project), it was not possible to unlock the inverter's features to set advance droop control parameters, mainly due to a lack of the manufacturer's support. Firmware upgrades and special manufacture permissions are required in order to implement and develop the droop control features in these commercial PV inverters. Regarding this, there is still a long way in which manufacturers, system operators and academia, need to work together before wide-spread voltage support services can be applied by the end users.

\section{CONCLUSION}

The tests reported in this paper were designed to investigate the feasibility of using power electronic equipment i.e., commercial PV inverters, to support voltage regulation in distribution networks, implemented using a droop-based APC-RPC strategy. According to the obtained results, it is possible to conclude that the efficiency of the inverter is not noticeably affected by changes in the reactive power output and remained steadily between $96 \%$ and $97 \%$. Thus, droop-based RPC does not affect the inverter's efficiency. Nevertheless, the efficiency showed a decline as a result of changes in the active power output. Regarding the inverter's response time, this is within the range expected from power electronics, thus, it can be conclude that it is sufficiently fast to be used for voltage support and management. Based on the real-time PHIL test presented, the interaction between the PV inverter and the distribution network was as expected. The PV inverter responded accordingly, following the voltage control strategy implemented, providing successfully the expected voltage support services. For future work, it is expected to study the interaction of multiple PV inverters and other equipment, such as on-load tap-changer transformers or bank capacitors, operating within the distribution network.

\section{ACKNOWLEDGMENT}

This research was developed within the project TKI Project $P Q$ in Control, proj. num. 10025230, in The Netherlands.

\section{REFERENCES}

[1] F. C. L. Trindade, T. S. D. Ferreira, M. G. Lopes, and W. Freitas, "Mitigation of fast voltage variations during cloud transients in distribution systems with PV solar farms," IEEE Trans. Power Delivery, vol. 32, no. 2, pp. 921-932, April 2017.

[2] D. A. Sarmiento, P. P. Vergara, L. C. P. da Silva, and M. C. de Almeida, "Increasing the PV hosting capacity with OLTC technology and PV VAr absorption in a MV/LV rural Brazilian distribution system," in 2016 17th International Conference on Harmonics and Quality of Power (ICHQP), Oct 2016, pp. 395-399.

[3] L. H. Macedo, J. F. Franco, R. Romero, M. A. Ortega-Vazquez, and M. J. Rider, "Increasing the hosting capacity for renewable energy in distribution networks," in 2017 IEEE Power Energy Society Innovative Smart Grid Technologies Conference (ISGT), April 2017, pp. 1-5. 


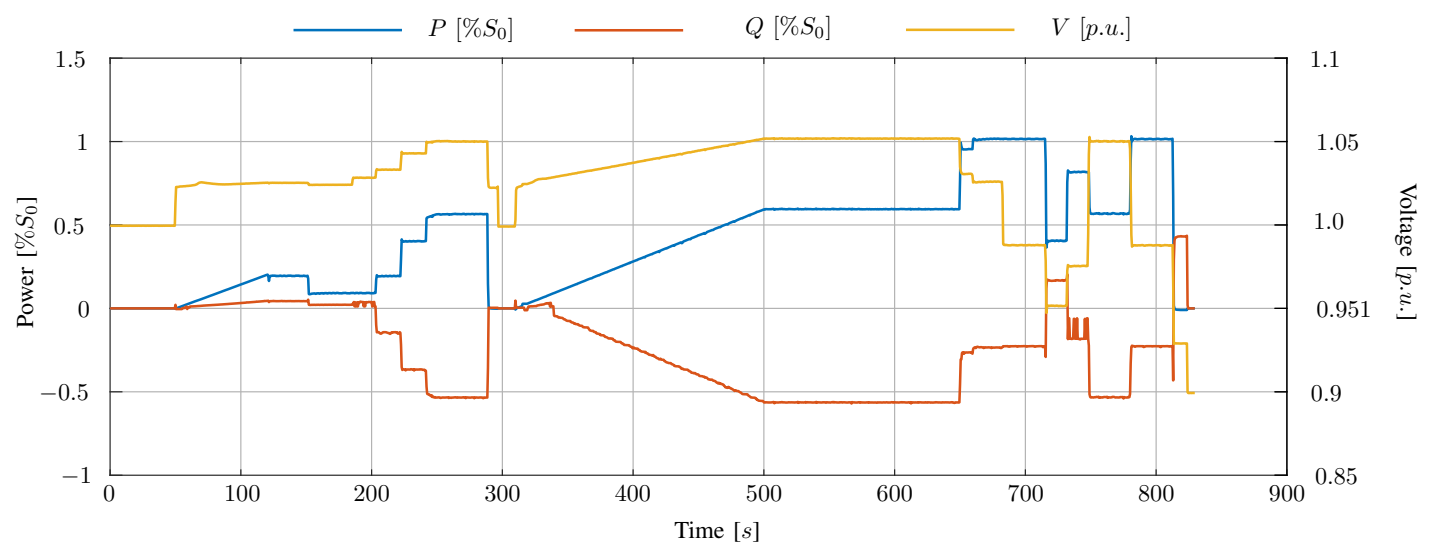

Figure 5. Measurements in the PHIL model after varying the irradiance and the grid voltage.

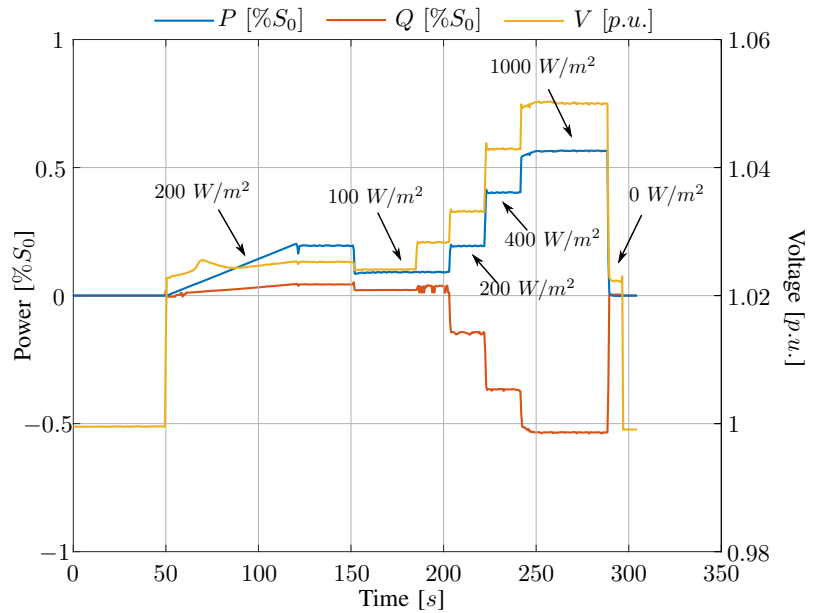

Figure 6. Inverter's response to changes in the irradiance before running online with the PHIL model.

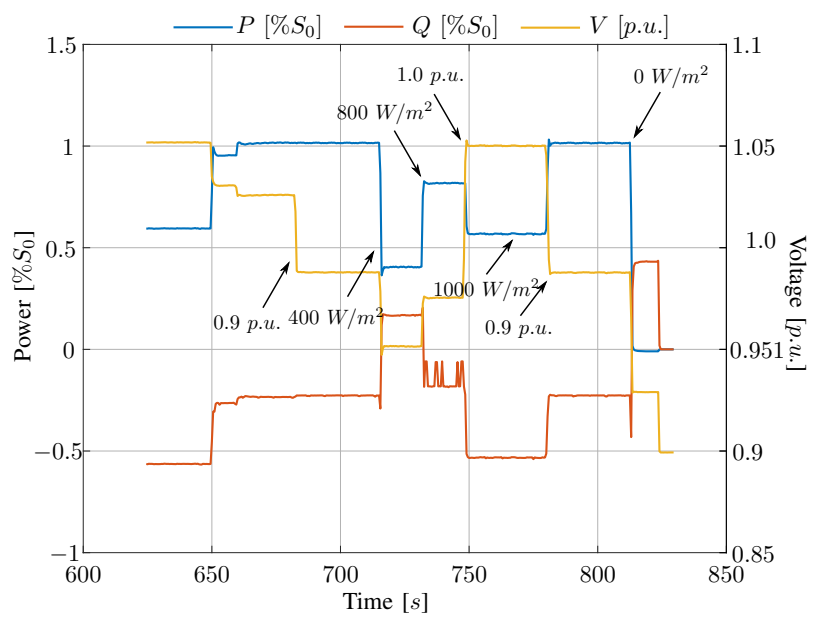

Figure 7. Inverter's response to changes in the irradiance and the grid voltage running online in the PHIL model.

[4] K. Turitsyn, P. Sulc, S. Backhaus, and M. Chertkov, "Options for control of reactive power by distributed photovoltaic generators," Proceedings of the IEEE, vol. 99, no. 6, pp. 1063-1073, June 2011.

[5] P. Chaudhary and M. Rizwan, "Voltage regulation mitigation techniques in distribution system with high PV penetration: A review," Ren. and Sust. Energy Reviews, vol. 82, pp. 3279 - 3287, 2018.

[6] P. Jahangiri and D. C. Aliprantis, "Distributed volt/var control by PV inverters," IEEE Trans. Power Systems, vol. 28, no. 3, pp. 3429-3439, Aug 2013.
[7] P. M. S. Carvalho, P. F. Correia, and L. A. F. M. Ferreira, "Distributed reactive power generation control for voltage rise mitigation in distribution networks," IEEE Trans. Power Systems, vol. 23, no. 2, pp. 766-772, May 2008.

[8] R. Tonkoski and L. A. Lopes, "Impact of active power curtailment on overvoltage prevention and energy production of pv inverters connected to low voltage residential feeders," Renewable Energy, vol. 36, no. 12, pp. $3566-3574,2011$.

[9] S. Ghosh, S. Rahman, and M. Pipattanasomporn, "Local distribution voltage control by reactive power injection from PV inverters enhanced with active power curtailment," in 2014 IEEE PES General Meeting । Conference Exposition, July 2014, pp. 1-5.

[10] L. Collins and J. Ward, "Real and reactive power control of distributed PV inverters for overvoltage prevention and increased renewable generation hosting capacity," Renewable Energy, vol. 81, pp. 464 - 471, 2015.

[11] R. Tonkoski and L. A. C. Lopes, "Voltage regulation in radial distribution feeders with high penetration of photovoltaic," in 2008 IEEE Energy 2030 Conference, Nov 2008, pp. 1-7.

[12] E. DallAnese, S. V. Dhople, and G. B. Giannakis, "Optimal dispatch of photovoltaic inverters in residential distribution systems," IEEE Trans. Sustainable Energy, vol. 5, no. 2, pp. 487-497, April 2014.

[13] E. DallAnese, S. V. Dhople, B. B. Johnson, and G. B. Giannakis, "Decentralized optimal dispatch of photovoltaic inverters in residential distribution systems," IEEE Trans. Energy Conversion, vol. 29, no. 4, pp. 957-967, Dec 2014.

[14] T. Senjyu, Y. Miyazato, A. Yona, N. Urasaki, and T. Funabashi, "Optimal distribution voltage control and coordination with distributed generation," IEEE Trans. Power Delivery, vol. 23, no. 2, pp. 1236-1242, April 2008.

[15] R. Tonkoski, L. A. C. Lopes, and T. H. M. El-Fouly, "Coordinated active power curtailment of grid connected PV inverters for overvoltage prevention," IEEE Trans. Sustainable Energy, vol. 2, no. 2, pp. 139-147, April 2011.

[16] M. V. M. Ali, M. Babar, P. Nguyen, and J. Cobben, "Overlaying control mechanism for solar PV inverters in the LV distribution network," Electric Power Systems Research, vol. 145, pp. 264 - 274, 2017.

[17] R. Tonkoski, L. A. C. Lopes, and T. H. M. EL-Fouly, "Droop-based active power curtailment for overvoltage prevention in grid connected PV inverters," in 2010 IEEE International Symposium on Industrial Electronics, July 2010, pp. 2388-2393.

[18] T. T. Mai, A. N. M. M. Haque, T. Vo, and P. H. Nguyen, "Coordinated active and reactive power control for overvoltage mitigation in physical LV microgrids," in 2018 International Conference on Renewable Power Generation, Sep. 2018, pp. 1-6.

[19] P. P. Vergara, J. C. Lopez, M. J. Rider, and L. C. P. da Silva, "Optimal operation of unbalanced three-phase islanded droop-based microgrids," IEEE Trans. Smart Grid, vol. 10, no. 1, pp. 928-940, Jan. 2019. 